\title{
Comparative evaluation of the microplate nitrate reductase assay and the rezasurin microtitre assay for the rapid detection of multidrug resistant Mycobacterium tuberculosis clinical isolates
}

\author{
Ahmet Yilmaz Coban ${ }^{1 /+}$, Meltem Uzun², Alper Akgunes ${ }^{3}$, Belma Durupinar ${ }^{1}$ \\ ${ }^{1}$ Department of Medical Microbiology, Medical School, Ondokuz Mayis University, Samsun, Turkey \\ ${ }^{2}$ Department of Medical Microbiology, Istanbul Medical School, Istanbul University, Istanbul, Turkey \\ ${ }^{3}$ Medical Microbiology Laboratory, Samsun Chest Diseases Hospital, Samsun, Turkey
}

\begin{abstract}
The microplate nitrate reductase assay (MNRA) and the rezasurin microtitre assay (REMA) were used for the susceptibility testing of 73 clinical isolates and the results were compared with those that were obtained using the Bactec 460 TB and Bactec MGIT 960 systems. The REMA and the MNRA were performed in 96-well plates. For the REMA, the concentrations of isoniazid (INH) and rifampicin (RIF) ranged from 1.0-0.01 $\mu \mathrm{g} / \mathrm{mL}$ and 2.0-0.03 $\mu \mathrm{g} / \mathrm{mL}$, respectively. For the MNRA, the INH concentration was between 1.0-0.03 $\mu \mathrm{g} / \mathrm{mL}$ and the RIF concentration was between 2.0-0.06 $\mu \mathrm{g} / \mathrm{mL}$. For the MNRA, the sensitivity, specificity, positive predictive value, negative predictive value and INH/RIF agreement were 100/95.6, 97.6/100, 96.8/100, 100/98 and 98.6/98.6, respectively, and for the REMA, they were 100/91.3, 90.4/100, 88.5/100, 100/96.1 and 94.5/97.2, respectively. Our data suggest that these two rapid, low-cost methods may be inexpensive, alternative assays for the rapid detection of multidrug resistant tuberculosis in low-income countries.
\end{abstract}

Key words: Mycobacterium tuberculosis - MIC determination - microplate nitrate reductase assay - rezasurin microtitre assay

Tuberculosis remains a global health problem due to the emergence of multidrug resistant (MDR) and extensive drug resistant isolates. Efficient diagnostic laboratories play an important role in helping to prevent the spread of disease amongst populations and in the selection of appropriate treatments (Martin et al. 2011). The proportion method using Middlebrook 7H10 agar, which is recommended by the National Committee for Clinical and Laboratory Standards Institute (NCCLSI 2003), is not used for susceptibility testing in developing countries due to its poor turnaround time. The Bactec 460 and Bactec MGIT 960 systems (Becton Dickinson Diagnostic Systems, Sparks, MD), which are two alternative methods that have been recommended by the CLSI, are also not used routinely in developing countries due to the associated costs and poor infrastructure (Palomino et al. 2002). Recently, there has been an increased effort to develop rapid and low-cost methods for susceptibility testing. The rezasurin microtitre assay (REMA) and the microplate nitrate reductase assay (MNRA) have been developed for rapid drug susceptibility testing and have been found to be concordant with standard methods (Martin et al. 2007, 2008).

This study aimed to assess the REMA and the MNRA for the rapid detection of MDR tuberculosis isolates, which are characterised by their resistances to isoniazid (INH) and rifampicin (RIF) minimally.

\footnotetext{
This study was presented as a poster at the 32th Annual Congress of the European Society of Mycobacteriology on 26th-29th June 2011 in Lübeck, Germany.

+Corresponding author: cobanay2003@gmail.com

Received 1 August 2011

Accepted 29 March 2012
}

\section{MATERIALS AND METHODS}

Strains - Seventy-three Mycobacterium tuberculosis samples, including 19 MDR isolates and H37Rv, ATCC 35820 (streptomycin resistant), ATCC 35822 (INH resistant), ATCC 35838 (RIF resistant) and ATCC 35837 (ethambutol resistant) standard strains were tested. Nineteen MDR strains were obtained from Istanbul University, Istanbul Medical School, Department of Medical Microbiology (Istanbul, Turkey) and susceptibility profiles of these isolates were obtained using the Bactec 460 TB System (Becton Dickinson Diagnostic Systems, Sparks, MD). Fifty-four strains that were susceptible to INH and RIF were obtained from Samsun Chest Diseases Hospital, Medical Microbiology Laboratory (Samsun, Turkey) and susceptibility profiles of these isolates were obtained using the Bactec MGIT 960 System (Becton Dickinson Diagnostic Systems, Sparks, MD).

Preparation of rezasurin - Rezasurin powder (Sigma-Aldrich, Inc, St Louis, USA) was dissolved in sterile distilled water at a final concentration of $0.02 \%$ and then sterilised by filtration and stored at $+4^{\circ} \mathrm{C}$ until use.

Preparation of Griess reagent - A solution including one part $50 \%$ hydrochloric acid, two parts $0.2 \%$ sulfanilamide and two parts $0.1 \%$ concentrated n-1-naphthylethylenediamine was prepared prior to use.

Preparation of bacterial inocula - Approximately five-six colonies that had been freshly grown on Löwenstein-Jensen media were inoculated into physiologic saline in tubes containing five- 10 glass beads and then vortexed for 1-2 $\mathrm{min}$. The tube was kept in a vertical position for $30 \mathrm{~min}$ at room temperature to allow for the sedimentation of aerosols and large particles. The turbidity of the supernatant was adjusted to that of the McFarland 
1 standard. The adjusted bacterial suspension was then diluted at a 1:10 ratio. One hundred microlitres of the dilution were used for the inoculation (Martin et al. 2011).

REMA - The test was performed in 96-well microtitre plates. Antibiotic solutions were prepared in the plates using a two-fold dilution series in Middlebrook $7 \mathrm{H} 9$ broth (containing $0.1 \%$ casiton, $0.5 \%$ glycerol and $10 \%$ OADC). The REMA showed that the INH and RIF ranges were $1.0-0.01 \mu \mathrm{g} / \mathrm{mL}$ and $2-0.03 \mu \mathrm{g} / \mathrm{mL}$, respectively. The plates were stored at $-80^{\circ} \mathrm{C}$ until use.

One hundred microlitres of bacterial suspension were inoculated into each well of the plates and incubated at $37^{\circ} \mathrm{C}$ in normal atmospheric conditions. Thirty microlitres of rezasurin solution were added into each well on the 7th day of incubation, after which the plates were incubated for one additional day. The minimum inhibitory concentrations (MICs) were determined according to colour changes at the end of incubation (Fig. 1).

MNRA - This assay was also performed in 96-well plates. Antibiotic solutions were prepared using two-fold dilutions in Middlebrook $7 \mathrm{H} 9$ broth (containing $0.1 \%$ casiton, $0.5 \%$ glycerol and $10 \%$ OADC), including 1.000 $\mu \mathrm{g} / \mathrm{mL}$ potassium nitrate. The MNRA indicated that the INH and RIF concentrations were between 1.0-0.03 $\mu \mathrm{g} /$ $\mathrm{mL}$ and $2.0-0.06 \mu \mathrm{g} / \mathrm{mL}$, respectively.

One hundred microlitres of bacterial suspension were inoculated into each well of the plates and incubated at $37^{\circ} \mathrm{C}$ in normal atmospheric conditions. Fifty microlitres of Griess reagent were then added into each of the control wells on the 7th day of incubation. When a purple colour was observed in the control wells, Griess reagent was also added into the test wells containing antibiotics and the MICs were determined according to the colour changes (Fig. 2).

The Bactec 460 TB and Bactec MGIT 960 systems were used as the standard methods to analyse the MDR and susceptible isolates, respectively. Both methods were performed as recommended by the manufacturers and the critical concentration of INH was $0.1 \mu \mathrm{g} / \mathrm{mL}$ for both. The critical concentration of RIF was $2.0 \mu \mathrm{g} / \mathrm{mL}$ for Bactec $460 \mathrm{~TB}$ and $1.0 \mu \mathrm{g} / \mathrm{mL}$ for Bactec MGIT 960.

\section{RESULTS}

In this study, the critical concentration was $0.5 \mu \mathrm{g} /$ $\mathrm{mL}$ for RIF and $0.25 \mu \mathrm{g} / \mathrm{mL}$ for INH. A strain is classified as resistant if the MIC value is $\geq 0.5$ for RIF and $\geq$ 0.25 for INH (Martin et al. 2011).

The MNRA results were reported immediately after Griess reagent was added on the 7th day of the study, while the REMA results were reported on the 8th day after inoculation due to the 24-h incubation that was required.

The results from this study were compared with those that were obtained using standard methods and studies with discordant results were repeated using the Bactec MGIT 960 and the REMA or the MNRA. In this study, four isolates were found to be resistant to INH by the REMA; however, they were found to be susceptible by the reference method (Table I). One isolate was found to be resistant to INH by the MNRA despite being found susceptible by the reference method (Table II). When the results of the REMA and MNRA were compared with those that were obtained using the standard methods to assess INH, the REMA showed a sensitivity of $100 \%$, a specificity of $90.4 \%$, a positive predictive value (PPV) of $88.5 \%$, an negative predictive value (NPV) of $100 \%$ and an agreement of $94.5 \%$ (Table I). Comparing the standard methods to the MNRA, these same parameters were determined to be $100 \%, 97.6 \%, 96.8 \%, 100 \%$ and $98.6 \%$, respectively (Table II).

RIF susceptibility testing showed that the two isolates were resistant using the reference method, whereas they were found to be susceptible using the REMA. One isolate was shown to be resistant to RIF by the refer-

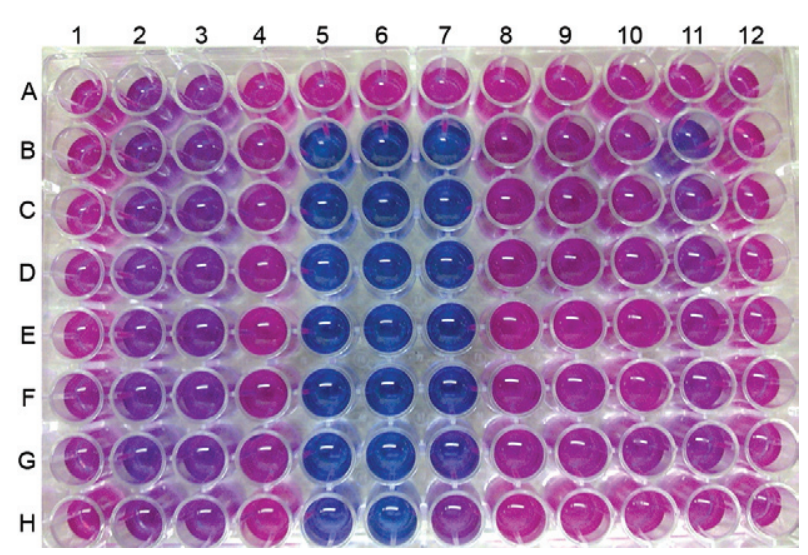

Fig. 1: assessment of rezasurin microtitre assay (REMA) results. A112: positive control wells; B1-12: $1.0 \mu \mathrm{g} / \mathrm{mL}$ for isoniazid (INH) and $2.0 \mu \mathrm{g} / \mathrm{mL}$ for rifampicin (RIF): $\mathrm{C} 1-12: 0.5 \mu \mathrm{g} / \mathrm{mL}$ for INH and $1.0 \mu \mathrm{g} /$ $\mathrm{mL}$ for RIF: D1-12: $0.25 \mu \mathrm{g} / \mathrm{mL}$ for INH and $0.5 \mu \mathrm{g} / \mathrm{mL}$ for RIF; E1-12: $0.125 \mu \mathrm{g} / \mathrm{mL}$ for INH and $0.25 \mu \mathrm{g} / \mathrm{mL}$ for RIF; F1-12: $0.06 \mu \mathrm{g} / \mathrm{mL}$ for INH and $0.125 \mu \mathrm{g} / \mathrm{mL}$ for RIF; G1-12: $0.03 \mu \mathrm{g} / \mathrm{mL}$ for INH and 0.06 $\mu \mathrm{g} / \mathrm{mL}$ for RIF; H1-12: $0.01 \mu \mathrm{g} / \mathrm{mL}$ for INH and $0.03 \mu \mathrm{g} / \mathrm{mL}$ for RIF.

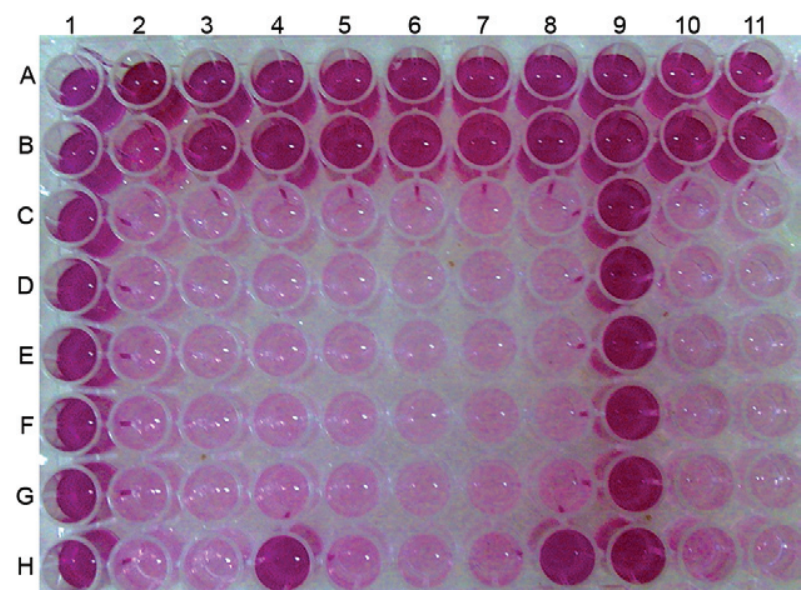

Fig. 2: assessment of microplate nitrate reductase assay (MNRA) results. A1-11: positive control wells; B1-11: positive control wells; C1-11: $1.0 \mu \mathrm{g} / \mathrm{mL}$ for isoniazid (INH) and $2.0 \mu \mathrm{g} / \mathrm{mL}$ for rifampicin (RIF); D1-11: $0.5 \mu \mathrm{g} / \mathrm{mL}$ for INH and $1 \mu \mathrm{g} / \mathrm{mL}$ for RIF; E1-11: 0.25 $\mu \mathrm{g} / \mathrm{mL}$ for INH and $0.5 \mu \mathrm{g} / \mathrm{mL}$ for RIF; F1-11: $0.125 \mu \mathrm{g} / \mathrm{mL}$ for INH and $0.25 \mu \mathrm{g} / \mathrm{mL}$ for RIF; G1-11: $0.06 \mu \mathrm{g} / \mathrm{mL}$ for INH and $0.125 \mu \mathrm{g} / \mathrm{mL}$ for RIF; H1-11: $0.03 \mu \mathrm{g} / \mathrm{mL}$ for INH and $0.06 \mu \mathrm{g} / \mathrm{mL}$ for RIF. 
ence method, whereas it was susceptible according to the MNRA. When the REMA results were compared with those that were obtained using the standard methods, the sensitivity was $91.3 \%$, the specificity was $100 \%$, the PPV was $100 \%$, the NPV was $96.1 \%$ and the agreement was $97.2 \%$ (Table I). A comparison of the MNRA to the standard methods revealed a sensitivity of $95.6 \%$, a specificity of $100 \%$, a PPV of $100 \%$, an NPV of $98 \%$ and an agreement of $98.6 \%$ (Table II).

\section{DISCUSSION}

The identification of INH and RIF resistances ensures the effective treatment of patients by permitting the early detection of MDR tuberculosis strains (Martin et al. 2007). The REMA and the MNRA are the most popular colourimetric methods that have been developed for this purpose.

In previous studies, the sensitivity and specificity of the REMA were calculated to be $93-100 \%$ and $96-100 \%$ for INH, while the sensitivity and specificity for RIF were $92-100 \%$ and $97-100 \%$, respectively. These previous studies had been conducted for duration of seven-14 days (Martin et al. 2007). Previous studies using the nitrate reductase test showed sensitivities and specificities that ranged from $87-100 \%$ and $95-100 \%$ for INH and from $94-100 \%$ and $100 \%$ for RIF; these results had been obtained following a period of between five-21 days (Martin et al. 2008).
Our study established that the sensitivity, specificity, PPV, NPV and agreement of the REMA and the MNRA for INH/RIF were 100/91.3\% and 100/95.6\%, 90.4/100\% and $97.6 / 100 \%, 88.5 / 100 \%$ and $96.8 / 100 \%, 100 / 96.1 \%$ and $100 / 98 \%$ and $94.5 / 97.2 \%$ and $98.6 / 98.6 \%$, respectively (Tables I, II). These results were obtained on the 7th day for the MNRA and 8th day for the REMA.

Although the nitrate reductase assay is usually performed on solid medium (Lowenstein-Jensen medium), Kumar et al. (2005) performed this test using the microplate method, similar to our study. They achieved levels of $99 \%$ agreement using the proportion method and obtained their results on the 8th day. Syre et al. (2003) performed the nitrate reductase assay using the macrodilution method and reported that the sensitivity and specificity were $100 \%$ and $94 \%$ for INH and $95 \%$ and $100 \%$ for RIF; their results were obtained on the 5 th day. Sanchotene et al. (2008) performed the nitrate reductase assay using the microdilution method and suggested that this assay could be used as a rapid and low-cost method, particularly in developing countries.

Both the REMA and the MNRA yielded concordant results compared with the standard methods in our study. In conclusion, both tests are rapid and inexpensive means of detecting MDR tuberculosis isolates. These colourimetric methods, sensitive as much as expensive methods, are suitable in resource poor-setting.

TABLE I

Comparing the results of REMA with those obtained with reference methods

\begin{tabular}{|c|c|c|c|c|c|c|c|c|}
\hline \multirow[b]{2}{*}{ Drug } & \multirow[b]{2}{*}{ REMA } & \multicolumn{2}{|c|}{ Reference method } & \multirow[b]{2}{*}{$\begin{array}{c}\text { Sensitivity } \\
(\%)\end{array}$} & \multirow[b]{2}{*}{$\begin{array}{c}\text { Specificity } \\
(\%)\end{array}$} & \multirow[b]{2}{*}{$\begin{array}{l}\text { PPV } \\
(\%)\end{array}$} & \multirow[b]{2}{*}{$\begin{array}{l}\text { NPV } \\
(\%)\end{array}$} & \multirow[b]{2}{*}{$\begin{array}{l}\text { Agreement } \\
(\%)\end{array}$} \\
\hline & & $\begin{array}{l}\text { Resistant } \\
(\%)\end{array}$ & $\begin{array}{c}\text { Susceptible } \\
(\%)\end{array}$ & & & & & \\
\hline \multirow[t]{2}{*}{ INH } & Resistant & 31 & 4 & 100 & 90.4 & 88.5 & 100 & 94.5 \\
\hline & Susceptible & 0 & 38 & - & - & - & - & - \\
\hline \multirow[t]{2}{*}{ RIF } & Resistant & 21 & 0 & 91.3 & 100 & 100 & 96.1 & 97.2 \\
\hline & Susceptible & 2 & 50 & - & - & - & - & - \\
\hline
\end{tabular}

INH: isoniazid; NPV: negative predictive value; PPV: positive predictive value; REMA: rezasurin microtitre assay; RIF: rifampicin.

TABLE II

Comparing the results of MNRA with those obtained with reference methods

\begin{tabular}{|c|c|c|c|c|c|c|c|c|}
\hline \multirow[b]{2}{*}{ Drug } & \multirow[b]{2}{*}{ MNRA } & \multicolumn{2}{|c|}{ Reference method } & \multirow[b]{2}{*}{$\begin{array}{c}\text { Sensitivity } \\
(\%)\end{array}$} & \multirow[b]{2}{*}{$\begin{array}{c}\text { Specificity } \\
(\%)\end{array}$} & \multirow[b]{2}{*}{$\begin{array}{l}\text { PPV } \\
(\%)\end{array}$} & \multirow[b]{2}{*}{$\begin{array}{c}\text { NPV } \\
(\%)\end{array}$} & \multirow[b]{2}{*}{$\begin{array}{l}\text { Agreement } \\
(\%)\end{array}$} \\
\hline & & $\begin{array}{c}\text { Resistant } \\
(\%)\end{array}$ & $\begin{array}{c}\text { Susceptible } \\
(\%)\end{array}$ & & & & & \\
\hline \multirow[t]{2}{*}{ INH } & Resistant & 31 & 1 & 100 & 97.6 & 96.8 & 100 & 98.6 \\
\hline & Susceptible & 0 & 41 & - & - & - & - & - \\
\hline \multirow[t]{2}{*}{ RIF } & Resistant & 22 & 0 & 95.6 & 100 & 100 & 98 & 98.6 \\
\hline & Susceptible & 1 & 50 & - & - & - & - & - \\
\hline
\end{tabular}

INH: isoniazid; MNRA: microplate nitrate reductase assay; NPV: negative predictive value; PPV: positive predictive value; RIF: rifampicin. 


\section{REFERENCES}

Kumar M, Khan IA, Verma V, Kalyan N, Qazi GN 2005. Rapid, inexpensive MIC determination of Mycobacterium tuberculosis isolates by using microplate nitrate reductase assay. Diagn Microbiol Infect Dis 53: 121-124.

Martin A, Paasch F, Docx S, Fissette K, Imperiale B, Ribón W, González LA, Werngren J, Engström A, Skenders G, Juréen P, Hoffner S, Del Portillo P, Morcillo N, Palomino JC 2011. Multicentre laboratory validation of the colorimetric redox indicator (CRI) assay for the rapid detection of extensively drug-resistant (XDR) Mycobacterium tuberculosis. J Antimicrob Chemother 66: 827-833.

Martin A, Panaiotov S, Portaels F, Hoffner S, Palomino JC, Angeby $\mathrm{K} 2008$. The nitrate reductase assay for the rapid detection of isoniazid and rifampicin resistance in Mycobacterium tuberculosis: a systematic review and meta-analysis. J Antimicrob Chemother 62: 56-64.

Martin A, Portaels F, Palomino JC 2007. Colorimetric redox-indicator methods for the rapid detection of multidrug resistance in $\mathrm{Myco}$ - bacterium tuberculosis: a systematic review and meta-analysis. J Antimicrob Chemother 59: 175-183.

NCCLS - National Committee for Clinical Laboratory Standards 2003. Susceptibility testing of Mycobacteria, Nocardia and other aerobic Actinomycetes. Approved Standard M24A, NCCLS, Wayne, 61 pp.

Palomino JC, Martin A, Camacho M, Guerra H, Swings J, Portaels F 2002. Resazurin microtiter assay plate: simple and inexpensive method for detection of drug resistance in Mycobacterium tuberculosis. Antimicrob Agents Chemother 46: 2720-2722.

Sanchotene KO, von Groll A, Ramos D, Scholante AB, Honscha G, Valenca M, Scaini CJ, da Silva PEA 2008. Comparative evaluation of the nitrate reductase assay and the resazurin microtitre assay for drug susceptibility testing of Mycobacterium tuberculosis against first line anti-tuberculosis drugs. Braz J Microbiol 39: 16-20.

Syre H, Phyu S, Sandven P, Bjorvatn B, Grewal HM 2003. Rapid colorimetric method for testing susceptibility of Mycobacterium tuberculosis to isoniazid and rifampin in liquid cultures. $J$ Clin Microbiol 41: 5173-5177. 